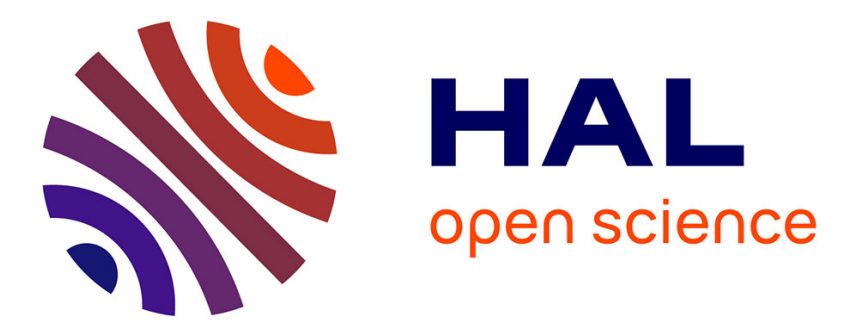

\title{
Effect of interdiffusion on mechanical and thermal expansion properties at high temperature of a MCrAlY coated Ni-based superalloy
}

\author{
Damien Texier, Daniel Monceau, Z. Hervier, Eric Andrieu
}

\section{To cite this version:}

Damien Texier, Daniel Monceau, Z. Hervier, Eric Andrieu. Effect of interdiffusion on mechanical and thermal expansion properties at high temperature of a MCrAlY coated Ni-based superalloy. Surface and Coatings Technology, 2016, vol. 307 (Part A), pp. 81-90. 10.1016/j.surfcoat.2016.08.059 . hal01564782

\author{
HAL Id: hal-01564782 \\ https://hal.science/hal-01564782
}

Submitted on 19 Jul 2017

HAL is a multi-disciplinary open access archive for the deposit and dissemination of scientific research documents, whether they are published or not. The documents may come from teaching and research institutions in France or abroad, or from public or private research centers.
L'archive ouverte pluridisciplinaire HAL, est destinée au dépôt et à la diffusion de documents scientifiques de niveau recherche, publiés ou non, émanant des établissements d'enseignement et de recherche français ou étrangers, des laboratoires publics ou privés. 


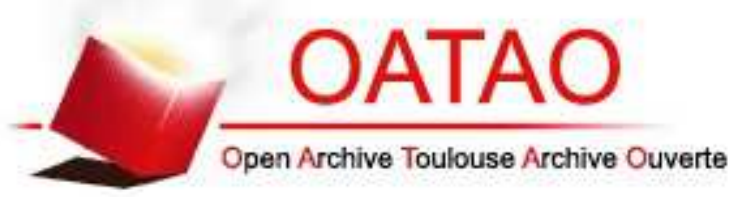

\section{Open Archive TOULOUSE Archive Ouverte (OATAO)}

OATAO is an open access repository that collects the work of Toulouse researchers and makes it freely available over the web where possible.

This is an author-deposited version published in : http://oatao.univ-toulouse.fr/ Eprints ID : 18108

To link to this article : DOI: 10.1016/j.surfcoat.2016.08.059

URL : http://dx.doi.org/10.1016/j.surfcoat.2016.08.059

To cite this version : Texier, Damien and Monceau, Daniel and Hervier, Z. and Andrieu, Eric Effect of interdiffusion on mechanical and thermal expansion properties at high temperature of a MCrAlY coated Ni-based superalloy. (2016) Surface and Coatings Technology, vol. 307 (Part A). pp. 81-90. ISSN 0257-8972

Any correspondence concerning this service should be sent to the repository administrator: staff-oatao@ listes-diff.inp-toulouse.fr 


\title{
Effect of interdiffusion on mechanical and thermal expansion properties at high temperature of a MCrAlY coated Ni-based superalloy
}

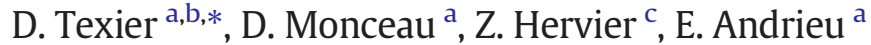 \\ a CIRIMAT, ENSIACET-INPT, 4, allée Emile Monso, BP 44362, F-31030 Toulouse Cedex4, France \\ ${ }^{\mathrm{b}}$ Mechanical Engineering Department, Ecole de Technologie Supérieure, 1100 Rue Notre-Dame Ouest, Montréal H3C 1K3, Québec, Canada \\ c Materials, Processes and Investigations Department, Safran Helicopter Engine, Avenue Joseph Szydlowski, 64510 Bordes, France
}

Keywords:

Ni-based superalloy

MCrAlY coating

Interdiffusion

Micromechanics

Tensile test

High temperature

\begin{abstract}
A B S T R A C T
Free-standing microtensile specimens were extracted from the substrate and the interdiffusion zone of a MCrAlY coated nickel-based single-crystal superalloy. Testing of these specimens was conducted at elevated temperatures, up to $1100{ }^{\circ} \mathrm{C}$ under controlled atmosphere, to assess the tensile and thermal expansion properties of the interdiffusion zone materials. These properties were measured and found to lie between the properties of the substrate and those of the coating. The poor mechanical strength of the interdiffusion zone evidenced its non-load bearing contribution to the system for uniaxial creep loading at high temperature representative of service conditions. It was also shown that the fabrication process of MCrAlY coated nickel-based superalloy affects the mechanical properties of the system due to the presence of voids and non-adherent grit-blasting particles within the interdiffusion zone.
\end{abstract}

\section{Introduction}

Gas turbine blades undergo severe service conditions with high mechanical and thermal loadings under aggressive atmospheres. The chemical composition and the microstructure of Ni-based single crystal superalloys have been optimized through different generations to resist creep deformation at high temperature [1,2]. To protect these materials from environmental degradations, i.e. isothermal and cyclic oxidation at high temperature and intermediate temperature corrosion, blades are generally coated. However, both the coating process and the heat treatments associated to the "as received" microstructure favor the interdiffusion between the coating and the superalloy [3]. Consequently, an interdiffusion zone forms into the superalloy inducing a complex multilayer material. The microstructure of each layer evolves under service conditions due to the combined effect of high temperature and mechanical stresses. The variation of the chemical composition in the different zones may affect their coefficient of thermal expansion. Composition evolution also modifies the lattice parameters of the $\gamma$ and $\gamma^{\prime}$ phases in the superalloy and therefore affects its microstructure and mechanical properties. Such microstructure modifications are expected to affect locally the creep resistance for which the superalloy was originally

\footnotetext{
* Corresponding author at: Ecole de Technologie Supérieure, 1100 Rue Notre-Dame Ouest, Montréal H3C 1K3, Québec, Canada.
}

E-mail address: damien.texier@etsmtl.ca (D. Texier). designed $[4,5]$. When designing engine parts, the coating can be acknowledged as weak compared to the superalloy substrate, and can therefore be considered as a peripheral non-load bearing zone. Because its properties are unknown, the interdiffusion layer can also be considered as a non-load bearing zone whose thickness is time and temperature dependent [6,7]. This last consideration is based on the comparison of steady-state creep rates and lifetimes of thin-walled coating specimens and bulk specimens. Such a design rule can be used as a first approximation for thin-walled coated structural parts. However, more advanced predictive models of the mechanical behavior of these coated materials, used for lifetime assessment, require databases of material properties for each layer affected by the interdiffusion. Bensch et al. investigated the effects of oxidation-induced chemical composition changes on the creep properties of single crystal Ni-based superalloys at elevated temperature $[4,5,8,9]$. They used alloys with chemical compositions matching those of superalloys after oxidation. In the present paper, effects of interdiffusion and coating were investigated using micrometric specimens extracted from real coated systems. These micrometric thick specimens were tested at temperatures representative of service conditions. In the literature, previous studies report several attempts to assess the micromechanical behavior of materials at high temperature, especially for coatings. Micro-indentation [10], micro-tensile [11-13], micro-pillar compression [14], shearing [15] or punch tests [16] were used to assess local mechanical properties of bond-coated superalloys. However, the mechanical strength and the 
thermal expansion properties of the substrate affected by the cross-diffusion with the coating, i.e. the interdiffusion zone, need further documentations.

The present study characterizes, at a local scale, the tensile and the thermal expansion behavior of each zone constituting the multilayer system using specific mechanical test rigs developed for this purpose [17-19].

\section{Materials and experimental approach}

\subsection{Materials}

The system studied is a MC2 first generation single-crystal Ni-based superalloy [20] coated with a $70 \mu \mathrm{m}$ thick NiCoCrAlYTa layer produced by TRIBOMET@ electrochemical deposition [21]. This deposition process consists of an electro-deposition of CrAlYTa particles entrapped in a $\mathrm{Ni}, \mathrm{Co}$ matrix

The MC2 rod was solidified by a withdrawal process along the [001] crystallographic direction and was submitted to a $3 \mathrm{~h}-1300^{\circ} \mathrm{C}$ solution heat treatment. The nominal composition (at.\%) of the Ni-based single crystal superalloy was $\mathrm{Ni}-8.9 \mathrm{Cr}-5.1 \mathrm{Co}-1.3 \mathrm{Mo}-2.5 \mathrm{~W}-10.7 \mathrm{~A} 1-1.8 \mathrm{Ti}-$ 2.0Ta. Plates were machined from the rod (width and thickness coincident with secondary dendritic arms directions and length aligned with primary dendritic arms - orientation within $7^{\circ}$ off [001]) and grit-blasted before coating. The mean chemical composition (at.\%) of the coating measured by quantitative EDX analysis was $\mathrm{Ni}-19.8 \mathrm{Cr}-17.2 \mathrm{Co}-0.2 \mathrm{Mo}-$ $0.5 \mathrm{~W}-17.2 \mathrm{~A} 1-0.1 \mathrm{Ti}-1.3 \mathrm{Ta}-0.8 \mathrm{Y}$. Aging heat treatments $\left(1080{ }^{\circ} \mathrm{C}-\right.$ $6 \mathrm{~h}+$ air cooling followed by $870{ }^{\circ} \mathrm{C}-20 \mathrm{~h}+$ air cooling) were finally conducted to ensure the optimization of creep microstructure of the superalloy and the chemical anchorage of the layers through interdiffusion. Three layers are commonly observed (Fig. 1): the monocrystalline substrate (S.Z.), the coated zone (C.Z.) and the interdiffusion zone (ID.Z.).

\subsection{Characterization techniques}

Specimens dedicated for observation were polished to $1 \mu \mathrm{m}$ using diamond paste. To reveal the $\gamma / \gamma^{\prime}$ microstructure, an electrolytic etching with 13 vol.\% $\mathrm{H}_{3} \mathrm{PO}_{4}, 45$ vol.\% $\mathrm{H}_{2} \mathrm{SO}_{4}$ and 42 vol.\% $\mathrm{HNO}_{3}$ was carried out under $5 \mathrm{~V}$ to preferentially consume the $\gamma$ phase. Microstructure analyses were conducted using a LEO435VP scanning electron microscope (SEM) operating at an accelerating tension of $15 \mathrm{kV}$. The emission current was $150 \mathrm{pA}$ and $2500 \mathrm{pA}$ for secondary electron (SEI) and backscattered electron (BSE) observations, respectively. EDX analyses were performed on a full system's cross sections with a JEOL JSM6400
SEM equipped with an Oxford EDAX analyzer. Probe current was first measured through a Faraday cage in order to guarantee $1.5 \mathrm{nA}$. The calibration of each constituent was carried out on real standards. Composition profile was quantified by averaging EDX signal on $5 \times 200 \mu \mathrm{m}^{2}$ boxes to include the different representative microstructural features.

\subsection{Mechanical characterization}

\subsubsection{Specimen preparation}

Free-standing specimens have been extracted from the coated superalloy system to characterize the mechanical properties at the elevated temperature of the monocrystalline substrate, the coated zone and the interdiffusion zone. Thirty-five-millimeter-long and 2-mm-wide ribbon shape specimens were first machined out with a STRUERS Secotom-50 high-precision cutting machine from the coated superalloy system. The longitudinal direction of the ribbon shape specimen was aligned with the withdrawal direction of the monocrystalline superalloy. Substrate (S.Z.) and interdiffusion zone (ID.Z.) specimens were prepared using a LOGITECH CL50 lapping machine associated with a PP5GT precision Jig, limiting the effect of grinding on the residual stresses and ensuring flatness of the specimens. Incremental polishing combined with microscope observations were used for the positioning at the original coating/surface interface in the case of ID.Z. specimens. The variation in thickness along the gage length is smaller than $\pm 0.5 \mu \mathrm{m}$. The complete procedure of specimen preparation is detailed in refs. [17, 18]. Substrate and interdiffusion zone specimen thicknesses were ranging from 124 to $130 \mu \mathrm{m}$ and 37 to $39 \mu \mathrm{m}$, respectively.

\subsubsection{High temperature tensile tests under controlled atmosphere}

Dedicated test rigs have been recently developed to perform mechanical tests at elevated temperature under controlled atmosphere on ultrathin specimens $[17,18]$. Specimens were gripped in self-tightening miniature grips. Tensile experiments were conducted under displacement control for an equivalent strain rate of $5 \times 10^{-5} \mathrm{~s}^{-1}$. Because of the small thickness of the specimens, the macroscopic strain was calculated from the measurement of grip displacement, performed with a KEYENCE LS7030M optical micrometer. Temperature measurements were carried out at two locations with very thin S-type thermocouples (76 $\mu \mathrm{m}$ diameter) spot-welded on platinum plates $(90 \mu \mathrm{m}$ thickness), located close to the gage length. Due to the very high surface/volume ratio of ultrathin specimens, surface degradation might considerably affect the mechanical properties of the material investigated. Environmental conditions were hence optimized to avoid surface degradations during mechanical testing such as oxidation or metal sublimation. Mechanical tests were conducted under a $120 \mathrm{kPa}$ high purity
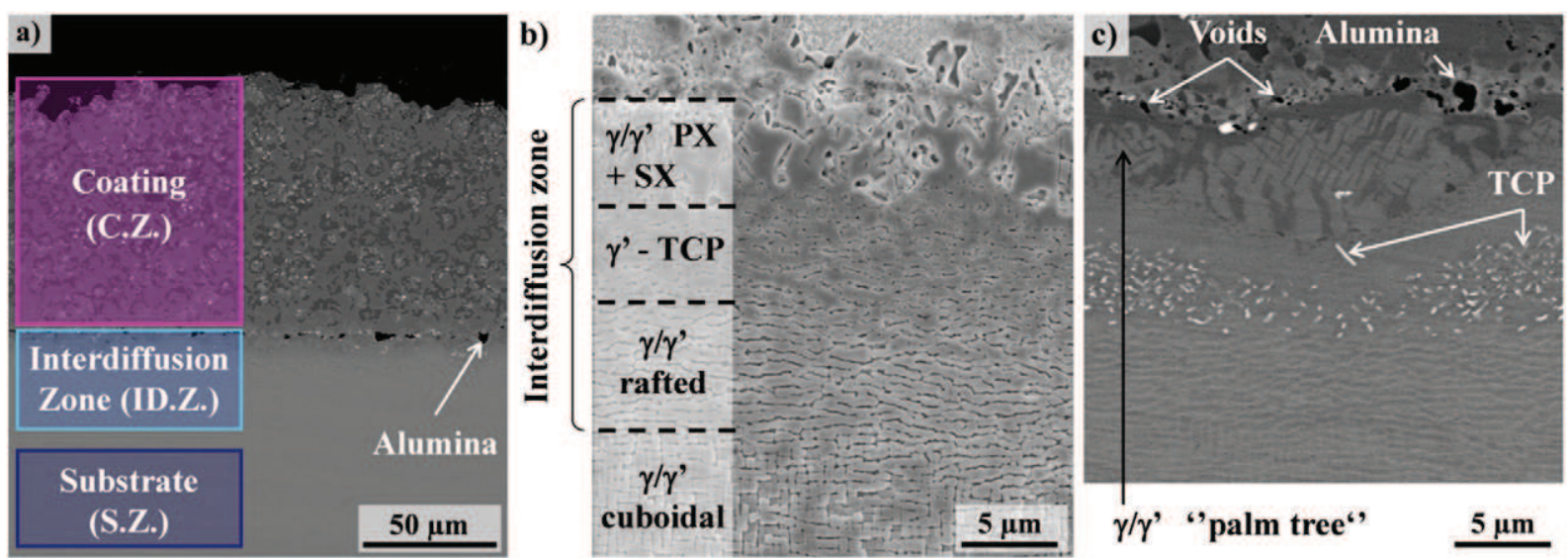

Fig. 1. a) General view of the gradient of microstructure of a NiCoCrAlYTa coated MC2 superalloy (BSE-SEM). Magnifications of the interdiffusion zone (ID.Z.): b) SEI-SEM observation of an etched specimen, c) BSE-SEM observation. The thickness and the extraction location of the ID.Z. specimen tested in the present study are illustrated as the blue rectangle in Fig. 1a. 
Ar static atmosphere combined with an oxygen getter made of particles of $\mathrm{Zr}$ to reduce the residual partial pressure of oxygen within the closed vessel. The present controlled atmosphere was demonstrated to greatly limit oxidation and sublimation of $\alpha$-alumina-forming alloys at $1100{ }^{\circ} \mathrm{C}$ for tens of hours. Both the mechanical test rig and the testing procedure are fully detailed in refs. $[17,18]$.

\subsubsection{Thermal expansion measurements}

Thermal expansion measurements of S.Z. and ID.Z. free-standing specimens have been conducted on the mechanical test rig detailed in Section 2.3.2 and in refs. [17,18] under controlled atmosphere. Dimensional variations of S.Z. and ID.Z. specimens were continuously measured with a KEYENCE LS7030M optical micrometer for a constant heating rate of $0.5 \mathrm{~K} \cdot \mathrm{s}^{-1}$. A constant tensile load $(1.5 \mathrm{~N})$ was monitored to ensure alignment of the specimen and the load trail. Blank measurements were previously performed for this heating rate in order to correct the thermal dimensional variation due to grip expansion.

\section{Results}

\subsection{Material characterization of the interdiffusion zone}

The microstructure of the interdiffusion zone is the result of the diffusion of chemical elements between the coating and the substrate during the aging heat treatments (Fig. 1b and c). In this study, a particular interest was put into the inner part of the interdiffusion zone, which is the zone of the superalloy affected by the presence of the coating. This zone is delimited by alumina particles coming from grit-blasting (black particles observed with the backscattered electron mode in the SEM in Fig. 1a and c). Indeed, these alumina particles are located at the initial position of the substrate-coating interface. (Ta,Ti) C precipitates (white particles in Fig. 1a and c) are exclusively located in the coating. They are formed by the reaction between fast diffusing carbon coming from the superalloy, Ta from the coating, and some Ti diffusing from the superalloy. These particles can help with the identification of the interdiffusion zone. A $\gamma / \gamma^{\prime}$ "palm tree"-like microstructure, due to the cellular recrystallization favored by residual stresses induced by grit blasting, appears below these particles and precipitates (Fig. 1c). This polycrystalline area (PX) grows during the aging heat treatment at $1080{ }^{\circ} \mathrm{C}$ [22]. Additionally, a $\gamma / \gamma^{\prime}$ layer is observed, it delimits both the zone of cellular recrystallization and the $\gamma^{\prime}$ layer "peppered" with TCP (topologically close-packed) phases (see white precipitates shown in Fig. 1c). Finally, a $\gamma / \gamma^{\prime}$ rafted microstructure, parallel to the coating-substrate interface, can be observed (denoted " $\gamma / \gamma^{\prime}$ rafted" in Fig. 1b). This phenomenon is induced by a residual bi-axial compressive state in the substrate prior to the coating deposit associated with gritblasting [22]. The P-type rafting induced by the heat treatment at $1080{ }^{\circ} \mathrm{C}$ is in accordance with the negative misfit existing between $\gamma$ and $\gamma^{\prime}$ phases at this temperature. The well-known cuboidal $\gamma / \gamma^{\prime}$ microstructure of SX Ni-based superalloys marks the end of the interdiffusion zone. This multilayered microstructure extends over $20 \mu \mathrm{m}$ in depth into the superalloy for the "as received" system, that is after the common heat treatment used for such engine parts.

The chemical composition profile from the coating to the substrate is given in Fig. 2. The gradient of chemical composition extends on both sides of the original interface affecting both the coating and the superalloy. Interestingly, tantalum and tungsten are segregated. The former is found at the interface due to $(\mathrm{Ta}, \mathrm{Ti}) \mathrm{C}$ precipitation and the latter at the diffusion front, inside the substrate, where TCP phases were formed. The diffusion front is located at the transition depth between the TCP region and the P-type rafted microstructure. Therefore, the P-type rafting cannot be attributed to any chemical composition modification affecting the lattice misfit between $\gamma^{\prime}$ precipitates and the surrounding $\gamma$ matrix. This confirms that P-type rafting is due to residual compressive stresses from the grit-blasting process.
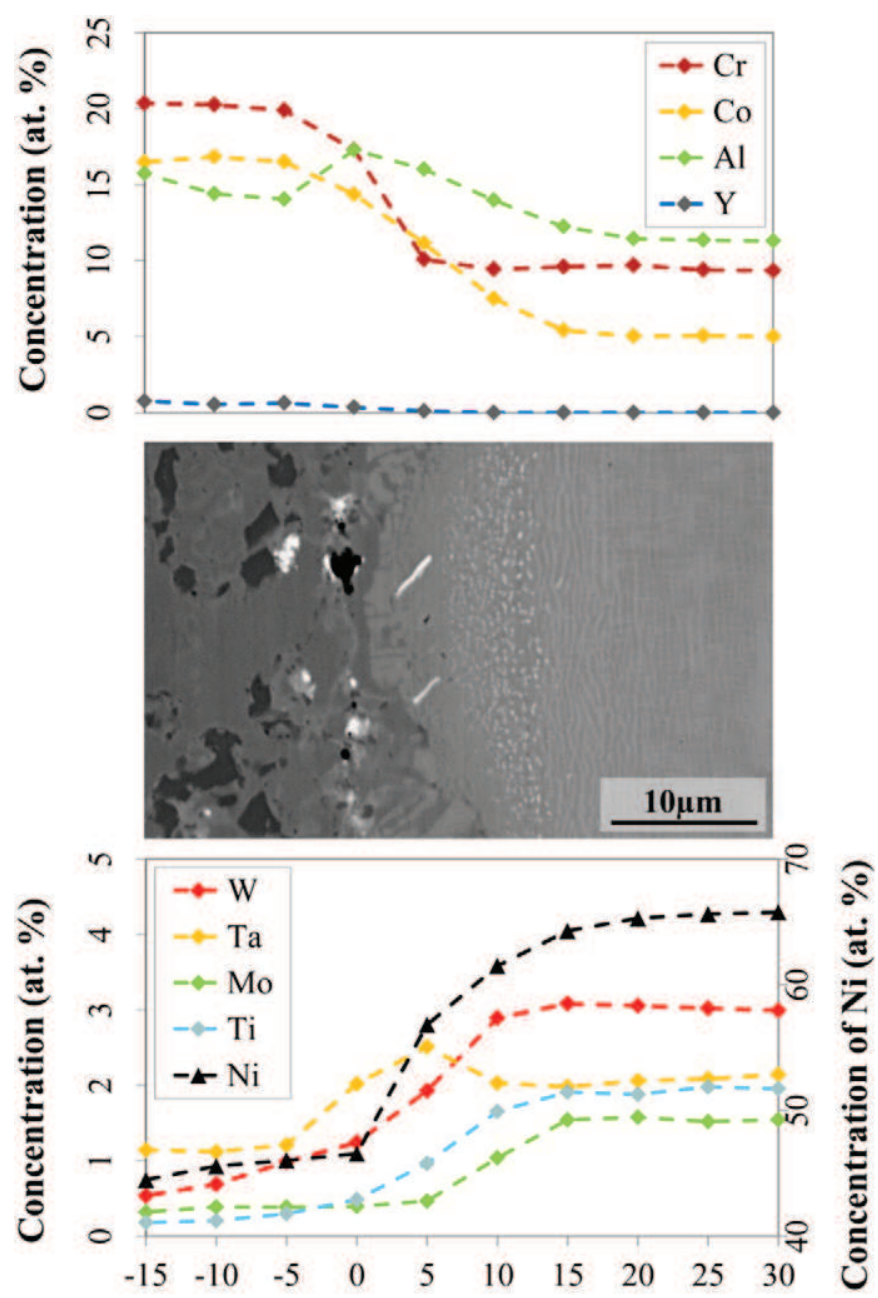

Relative position to the interface $(\mu \mathrm{m})$

Fig. 2. Chemical profile of the interdiffusion zone within a MCrAlY coated MC2 superalloy.

\subsection{Effect of preparation on ID.Z. specimens}

Specimen preparation has a strong impact on the reliability of the mechanical characterization, especially for specimens extracted from the interdiffusion zone. The interdiffusion zone presented a multilayered microstructure. Thus, proper attention has been paid to control the thickness and the extraction location of ID.Z. specimens within the multilayer system. Fig. 3 highlights the accuracy of the extraction procedure. Fig. 3a and b respectively represent the cross-section and the top view of a specimen extracted from the interdiffusion zone. Cross-section observations of interdiffusion-zone specimens enabled an additional verification of the ID.Z. specimens' thickness (ranging from 37 to $39 \mu \mathrm{m}$ for the interdiffusion zone) and their exact extraction location. The original interface between the coating and the superalloy was "peppered" with alumina particles coming from grit-blasting of the substrate prior to the deposition process. Grit-blasting particles can be observed both on the top view and on the cross section of the specimen (see black particles in Fig. 3). Fig. 3b shows that most of the specimen surface is located at the interface (area "peppered" with alumina) and that edges of specimens are blunted on $150 \mu \mathrm{m}$ with a maximal depth of $4 \mu \mathrm{m}$ at the extremity. For each specimen, the SEM observation of the surface provides enough information to estimate the surface area covered by the "interface region". It was found that 70 to $85 \%$ of the surface 

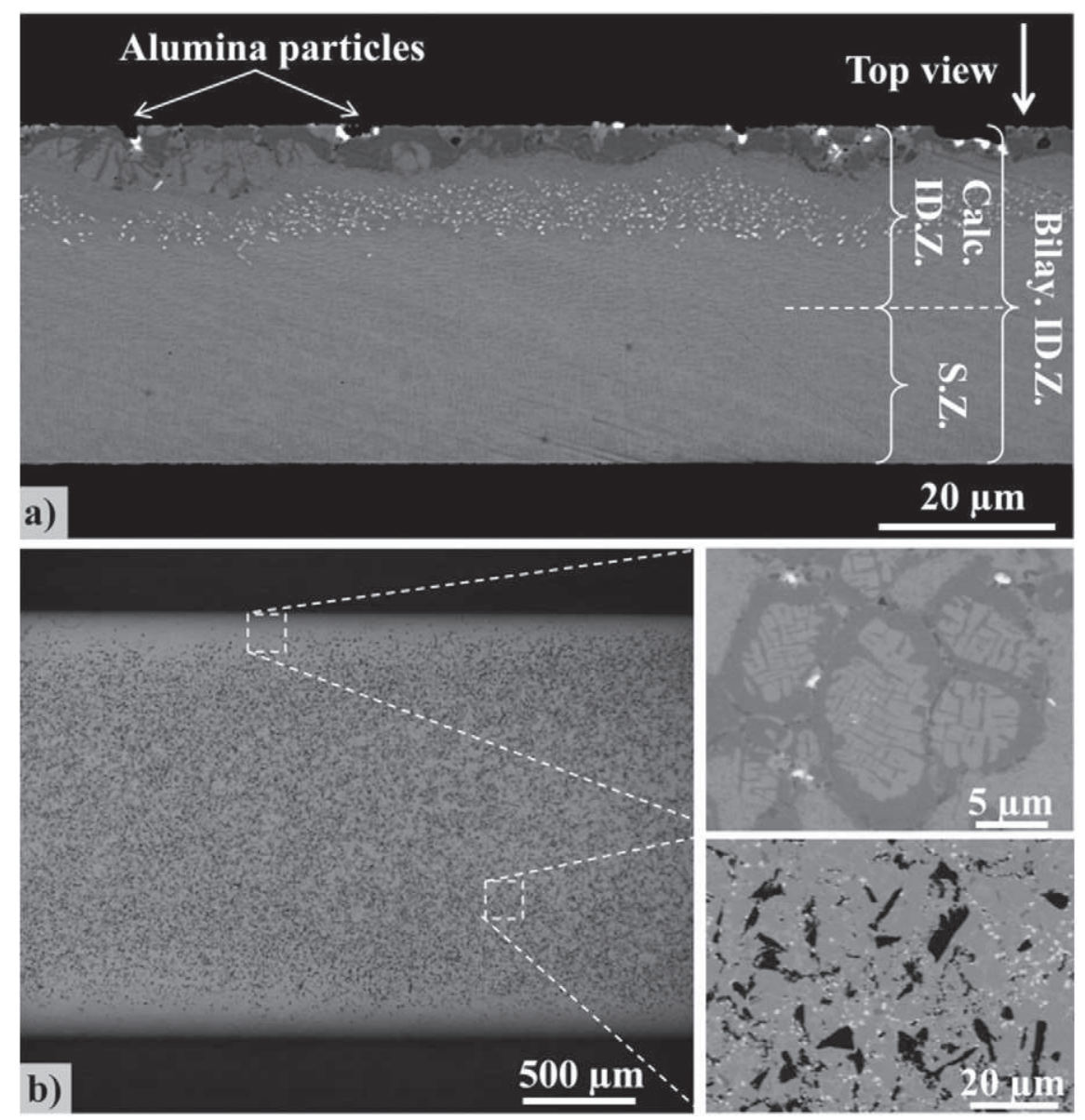

Fig. 3. a) Cross section of an ID.Z. specimen (BSE-SEM). b) Top view of an ID.Z. specimen (BSE-SEM). Magnifications on the grit-blasted "interface" (bottom) and on the cellular recrystallization region (top).

area is covered by an "interface region". The rest corresponds to the "cellular recrystallization" zone.

ID.Z. specimens were 37-39 $\mu$ m thick whereas the thickness of the affected microstructure of the superalloy did not exceed $20 \mu \mathrm{m}$. Consequently, ID.Z. specimens are made of a significant fraction of superalloy base material, that is 46 to $49 \%$ in area fraction measured with cross-section SEM observations. A bilayer approach was then used to estimate the tensile behavior of the interdiffusion zone. The bilayered ID.Z. specimens and the calculated ID.Z. material were denoted "bilay. ID.Z." and "calc. ID.Z.", respectively. These denominations are reported in Fig. 3a.

\subsection{Tensile behavior}

Tensile tests were conducted on S.Z. specimens and free-standing bilayered ID.Z. specimens at $950{ }^{\circ} \mathrm{C}, 1050{ }^{\circ} \mathrm{C}$ and $1100{ }^{\circ} \mathrm{C}$. Fig. $4 \mathrm{a}$ and b
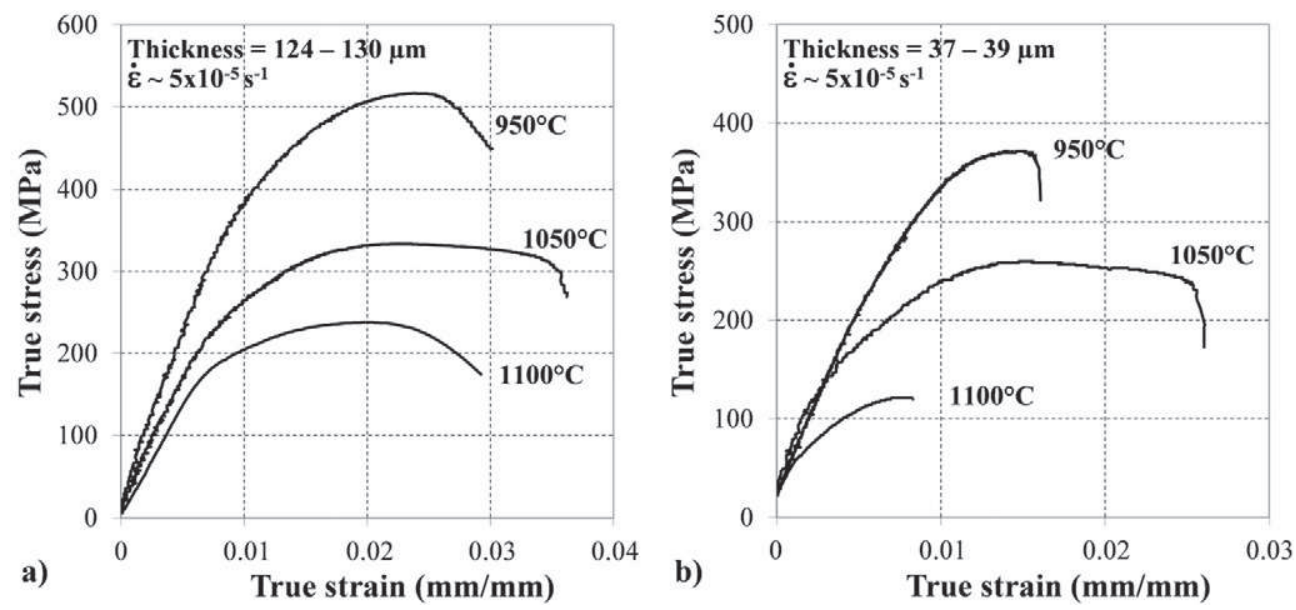

Fig. 4. Tensile experiments performed on free-standing specimens at 950,1050 and $1100{ }^{\circ} \mathrm{C}$ : a) S.Z. specimens, b) bilayer ID.Z. specimens. 
present stress-strain curves associated with each kind of specimen. Both the $0.2 \%$ offset yield strength (Y.S.) and ultimate tensile strength (U.T.S.) of each layer decreased with the temperature in the investigated temperature range. The mechanical strength (Y.S. and U.T.S.) of both S.Z. and ID.Z. specimens are given according to the temperature in Fig. 5. The tensile strength of S.Z. specimens were compared with bulk specimen results reported in the literature, depicted as colored domains in Fig. 5 [23]. Tests on bulk MC2 specimen were performed at two strain rates: $1 \times 10^{-5} \mathrm{~s}^{-1}$ (bottom limit of each colored domain) and $1 \times 10^{-4} \mathrm{~s}^{-1}$ (top limit) [23]. S.Z. specimens were found to have a comparable Y.S. but a slightly lower U.T.S. than bulk specimens. To the authors' knowledge, no tensile properties of such an interdiffusion zone have been reported in the literature.

Compared to the superalloy base material, the observed interdiffusion zone presents a lower mechanical resistance for the investigated temperature range, i.e. $0.2 \%$ yield strength (Y.S.), ultimate tensile strength (U.T.S.) and ductility. Concerning the tensile behavior of the bilayered ID.Z., an isostrain model approach (Voigt analytical model) has then been used to estimate the mechanical properties of this $20 \mu \mathrm{m}$ thick affected zone (calc. ID.Z. in Fig. 3a). Assuming the continuity of the deformation in both layers, stress within the interdiffusion zone is estimated with Eq. (1).

$\sigma_{\text {Calc.ID.Z. }}(\varepsilon)=\left(\sigma_{\text {Bilay.ID.Z. }}(\varepsilon) \cdot S_{\text {Bilay.ID.Z. }}-\sigma_{\text {S.Z. }}(\varepsilon) \cdot S_{S . Z .}\right) / S_{I D . Z \text {. }}$

$\sigma_{i}(\varepsilon)$ and $S_{i}$ are respectively the homogeneous stress in the layer $i$ at a given strain and the section of the material $i$. The tensile strength (Y.S. and U.T.S.) of calc. ID.Z. is reported in Fig. 5 as gray solid and dashed lines. Since the substrate exhibits a higher tensile strength in this range of temperature than the bilayered ID.Z. specimen, calc. ID.Z. (gray solid and dashed lines) subsequently demonstrates lower tensile strength than the bilayered ID.Z. specimen (blue solid and dashed lines). These properties are reported in Table 1.

The tensile properties of the superalloy obtained from tensile testing on S.Z. specimens are used as a reference for 2D and 3D finite element (FEA) calculations. The FEA calculations were performed with ABAQUS 6.13 for comparison with the isostrain analytical model. CPE4R

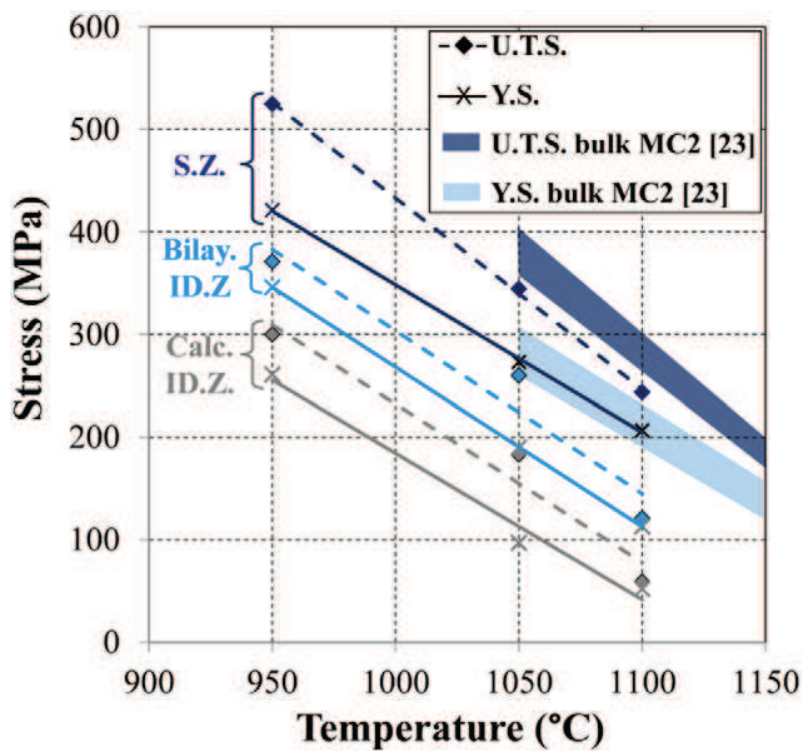

Fig. 5. $0.2 \%$ offset yield strength (Y.S.) and ultimate tensile strength (U.T.S.) of S.Z. specimens, bilayer ID.Z. specimens and calculated ID.Z. specimens as a function of temperature. Comparison with MC2 tensile behavior obtained on bulk specimens for strain rates of $1 \times 10^{-5} \mathrm{~s}^{-1}$ (lower limit of the colored domains) and $1 \times 10^{-4} \mathrm{~s}^{-1}$ (lower limit of the colored domains) [23].
Table 1

Tensile properties (yield strength (Y.S.) and ultimate tensile strength (U.T.S.)) of the different layers as a function of temperature.

\begin{tabular}{|c|c|c|c|c|c|c|c|c|}
\hline \multirow{3}{*}{$\begin{array}{l}\text { Temperature } \\
\left({ }^{\circ} \mathrm{C}\right)\end{array}$} & \multicolumn{4}{|c|}{ Y.S. (MPa) } & \multicolumn{4}{|c|}{ U.T.S. (MPa) } \\
\hline & \multirow{2}{*}{$\frac{\text { S.Z. }}{\text { Exp. }}$} & \multirow[b]{2}{*}{$\begin{array}{l}\text { Bilay. } \\
\text { ID.Z. }\end{array}$} & \multicolumn{2}{|l|}{ Calc. ID.Z. } & \multirow{2}{*}{$\frac{\text { S.Z. }}{\text { Exp. }}$} & \multirow[b]{2}{*}{$\begin{array}{l}\text { Bilay. } \\
\text { ID.Z. }\end{array}$} & \multicolumn{2}{|l|}{ Calc. ID.Z. } \\
\hline & & & Isostrain & $\begin{array}{l}3 \mathrm{D} \\
\text { FEA }\end{array}$ & & & Isostrain & $\begin{array}{l}3 \mathrm{D} \\
\text { FEA }\end{array}$ \\
\hline 950 & 421 & 346 & 261 & 259 & 525 & 371 & 300 & 295 \\
\hline 1050 & 273 & 190 & 97 & 97 & 344 & 260 & 183 & 181 \\
\hline 1000 & 207 & 113 & 52 & 51 & 243 & 113 & 59 & 57 \\
\hline
\end{tabular}

rectangular elements and C3D8R parallelepiped elements were chosen to mesh the bilayer system for the 2D and 3D calculations, respectively. The substrate/interdiffusion zone thickness ratio was respected for each specimen. Isotropic elastic and plastic tensile behaviors were chosen for the interdiffusion zone (isostrain calculation from the ID.Z. specimen) and the substrate (experimental data from the S.Z. specimen) for each temperature. The occurrence of grit-blasting particles and voids was not taken into account in the FEA calculations. Due to symmetries of the system, only a quarter of the specimen was modeled and symmetry conditions were applied. Incremental displacements of the nodes at the extremity of the specimen were imposed in order to achieve $5 \times 10^{-4}$ total strain between each step. The macroscopic stress was considered as the average value of the principal longitudinal stresses $S_{11}$ at the different nodes of the mid-specimen section normal to the loading direction. The calculated stress-strain curves of the bilayer specimen at $950{ }^{\circ} \mathrm{C}$ are plotted in Fig. 6. No significant differences were found between the three calculation methods for the different temperatures $\left(<4 \mathrm{MPa}\right.$ at $\left.950{ }^{\circ} \mathrm{C}\right)$. The estimated tensile properties (isostrain model) of the interdiffusion zone are reported in Fig. 5 and Table 1 and compared with the tensile behavior of the bilayered interdiffusion zone and the superalloy. In comparison with the superalloy, a drop on the yield stress of the interdiffusion zone (Calc. ID.Z.) of about $155 \mathrm{MPa}$ is observed in the investigated temperature range.

\subsection{Thermal expansion properties of the different layers}

Thermal expansion measurements were conducted on S.Z. and ID.Z. specimens from room temperature to $1000{ }^{\circ} \mathrm{C}$. Fig. 7 presents the instantaneous thermal expansion of these materials according to the temperature. The thermal expansion of a bulk MC2 specimen [24] has been plotted as a black dashed line in Fig. 7 and is consistent with the one obtained for the ultrathin S.Z. specimen. The bilayered interdiffusion specimen exhibits a higher thermal expansion than the superalloy base material. A bilayer approach was used to estimate the thermal expansion of the interdiffusion zone (Eq. (2)), assuming that no bending occurs during the thermal expansion experiment due to the $1.5 \mathrm{~N}$ load applied.

$\alpha_{\text {Calc.ID.Z. }}(T)=\frac{\varepsilon_{\text {Bilay.ID.Z. }}(T)}{\Delta T}+\frac{\left(\varepsilon_{\text {Bilay.ID.Z.. }}(T)-\alpha_{\text {S.Z. }}(T) \cdot \Delta T\right) \cdot E_{S . Z .}(T) \cdot S_{\text {S.Z. }}}{E_{\text {Calc.ID.Z. }}(T) \cdot S_{\text {ID.Z. }} \cdot \Delta T}$

$\alpha_{i}(T), \varepsilon_{i}(T), E_{i}$ and $S_{i}$ are respectively the thermal expansion, the total strain, the Young modulus and the section of the material $i$. The corrected interdiffusion (Calc. ID.Z.) thermal expansion is plotted in Fig. 7 using a blue dashed line. The thermal expansion of the calculated interdiffusion zone is higher than the thermal expansion of the superalloy and of the bilayered interdiffusion zone. The thermal expansion of the NiCoCrAlYTa coating is reported in Fig. 7 for direct comparison (pink dashed line for a bulk NiCoCrAlYTa specimen [25] and pink solid line for a free-standing thin NiCoCrAlYTa specimen obtained with the present technique [18]). Results indicate that the interdiffusion zone has intermediate thermal expansion properties between the coating and the superalloy. 

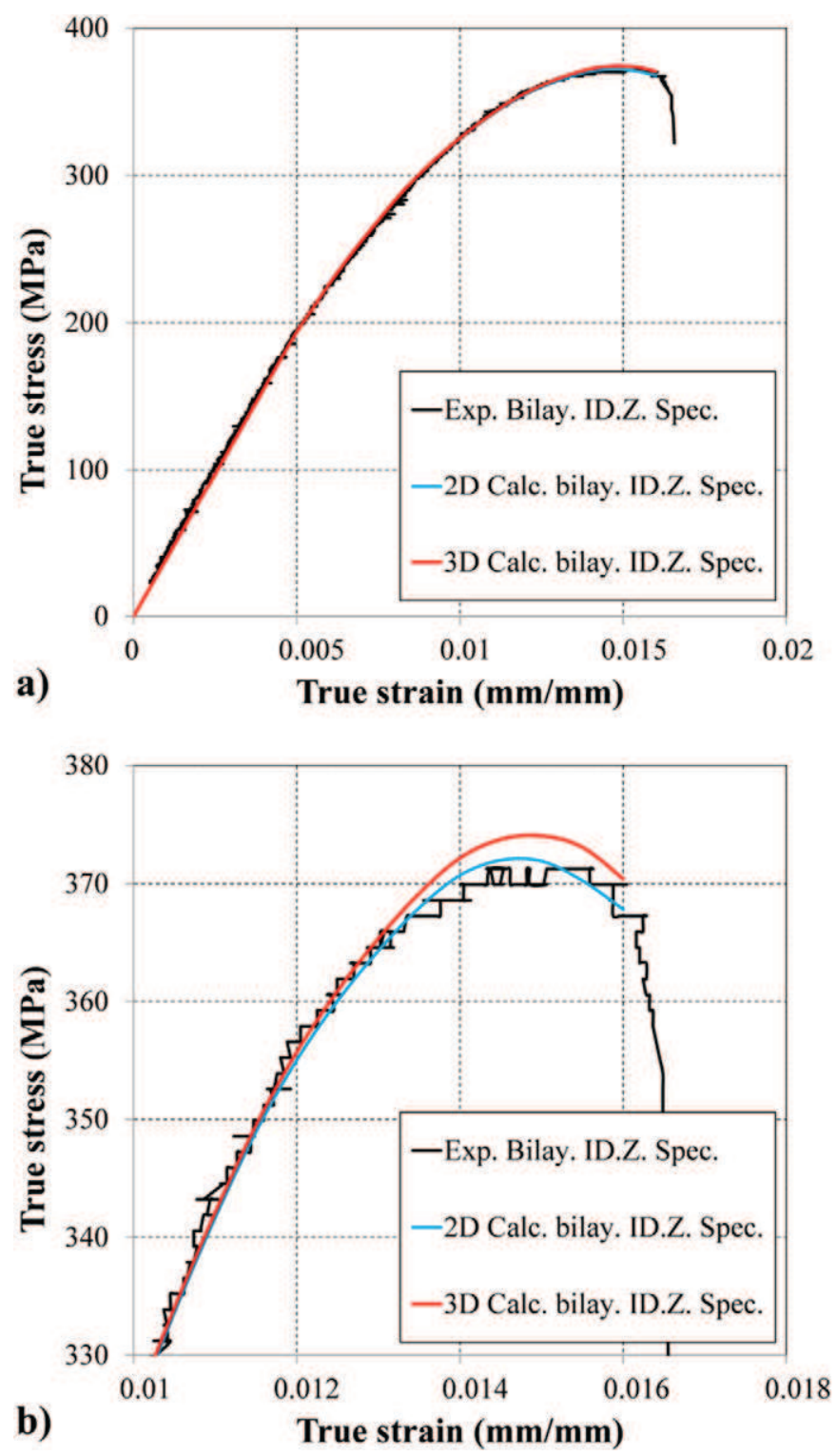

Fig. 6. a) Stress-strain behavior of the bilayered ID.Z. specimen at $950{ }^{\circ} \mathrm{C}$ calculated with 2D and 3D finite element analyses compared with experimental data. b) Slight differences in stress-strain curves in the high-stress regime of the bilayered ID.Z. specimen at $950{ }^{\circ} \mathrm{C}$ calculated with $2 \mathrm{D}$ and 3D FEA and compared with experimental data. The serration observed on the experimental plot is due to non-filtered dimensional measurements and the resolution of the load-cell measurements.

The average linear coefficients of thermal expansion (CTE) were calculated from the instantaneous thermal expansion measurements and reported in Table 2. The CTEs of the interdiffusion zone and of the superalloy base material increase with the temperature. Our results are consistent with the literature that reports higher CTE for coatings than for superalloys [24-29].

\subsection{Fracture area}

Low and high magnification SEM observations were performed after failure. Fig. 8 presents fracture surfaces for S.Z. and ID.Z. specimens after tensile testing at $1050^{\circ} \mathrm{C}$. Despite the high length and width of the specimens when compared to their thickness, no twisting of the specimens was observed for a homogeneous S.Z. specimen (Fig. 8a). Twisting was encountered for ID.Z. specimens presenting a gradient of microstructure and chemical composition through the thickness (Fig. 8d). In addition, S.Z. and ID.Z. specimen fracture surfaces exhibited areas where the

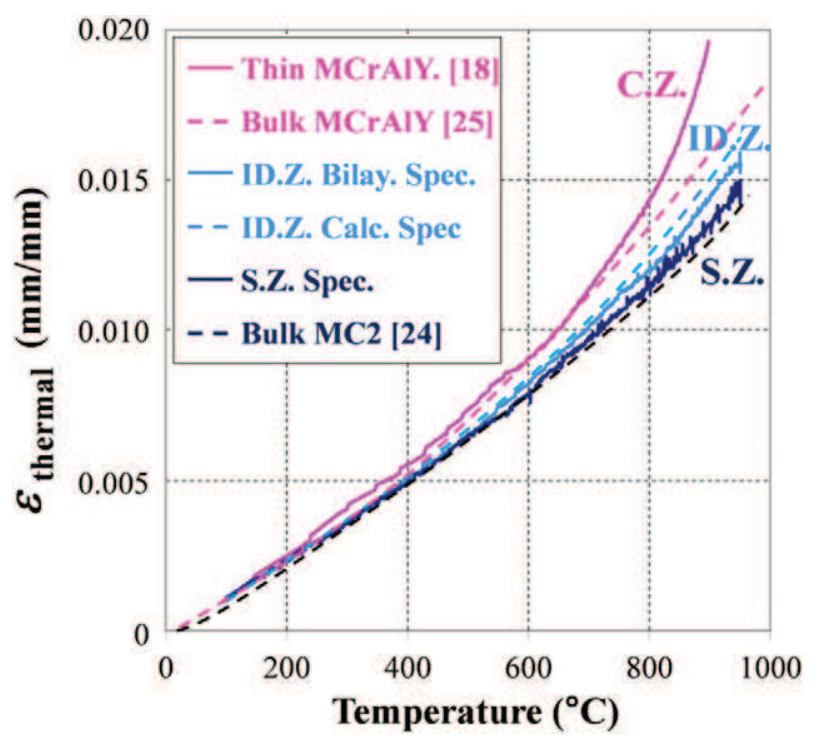

Fig. 7. Thermal expansion of S.Z. specimens, bilayer ID.Z. specimens (solid line) and calculated ID.Z. specimens (blue dashed line) as a function of temperature. Comparison with thermal expansion behavior of MCrAlY (pink solid line from ref. [18] for thin freestanding specimen and pink dashed line from ref. [25] for bulk specimen) and MC2 (black dashed line from ref. [24]) obtained on bulk specimens.

necking occurred along the entire surface and areas where slightly deformed pores were observed (see e.g. Fig. $8 \mathrm{~b}$ and e). As depicted in Fig. $8 \mathrm{a}$ and $\mathrm{d}$, the ID.Z. specimen displays a higher fraction of pores than the S.Z. specimen. Pores locations are shown with arrows in Fig. $8 \mathrm{~d}$. Three to five pores were noticed on the fracture areas of the S.Z. specimen when more than thirty pores where observed on the fracture surface of the ID.Z. specimen.

\section{Discussion}

\subsection{Thermal expansion and tensile behaviors of the interdiffusion zone}

Results indicate that tensile and thermal expansion behaviors of the superalloy base material underneath the coating/substrate interface are affected by interdiffusion and the deposition process. A significant drop in yield stress of the interdiffusion zone was noticed for the investigated temperature range in comparison with the ones of the superalloy. This decrease in yield stress can be the result of microstructural evolutions within the interdiffusion due to the contribution of both the fabrication process and the diffusion of chemical elements between the coating and the superalloy. The microstructure within the interdiffusion zone consists of a polycrystalline microstructure with a non- $\gamma / \gamma^{\prime}$ strengthening layer and with the occurrence of TCP phases. It differs from the optimized cuboidal $\gamma / \gamma^{\prime}$ single crystal microstructure of the base superalloy. In addition, both the tensile and the thermal expansion properties of the NiCoCrAlYTa coating used in the present study were recently

Table 2

Coefficients of thermal expansion of the different layers as a function of temperature.

\begin{tabular}{lllll}
\hline Temperature $\left({ }^{\circ} \mathrm{C}\right)$ & \multicolumn{2}{l}{$\alpha\left(10^{-6}{ }^{\circ} \mathrm{C}^{-1}\right)$} & \\
\cline { 2 - 5 } & S.Z. & Bilay. ID.Z. & Calc. ID.Z. & C.Z. \\
\hline$[25-600]$ & 13.5 & 13.9 & 14.3 & 15.1 \\
700 & 14.3 & 14.6 & 15.5 & 16.2 \\
800 & 14.8 & 15.3 & 16.3 & 17.9 \\
900 & 15.4 & 16.0 & 17.3 & 22.0 \\
1000 & 16.3 & 16.7 & 18.2 & - \\
\hline
\end{tabular}



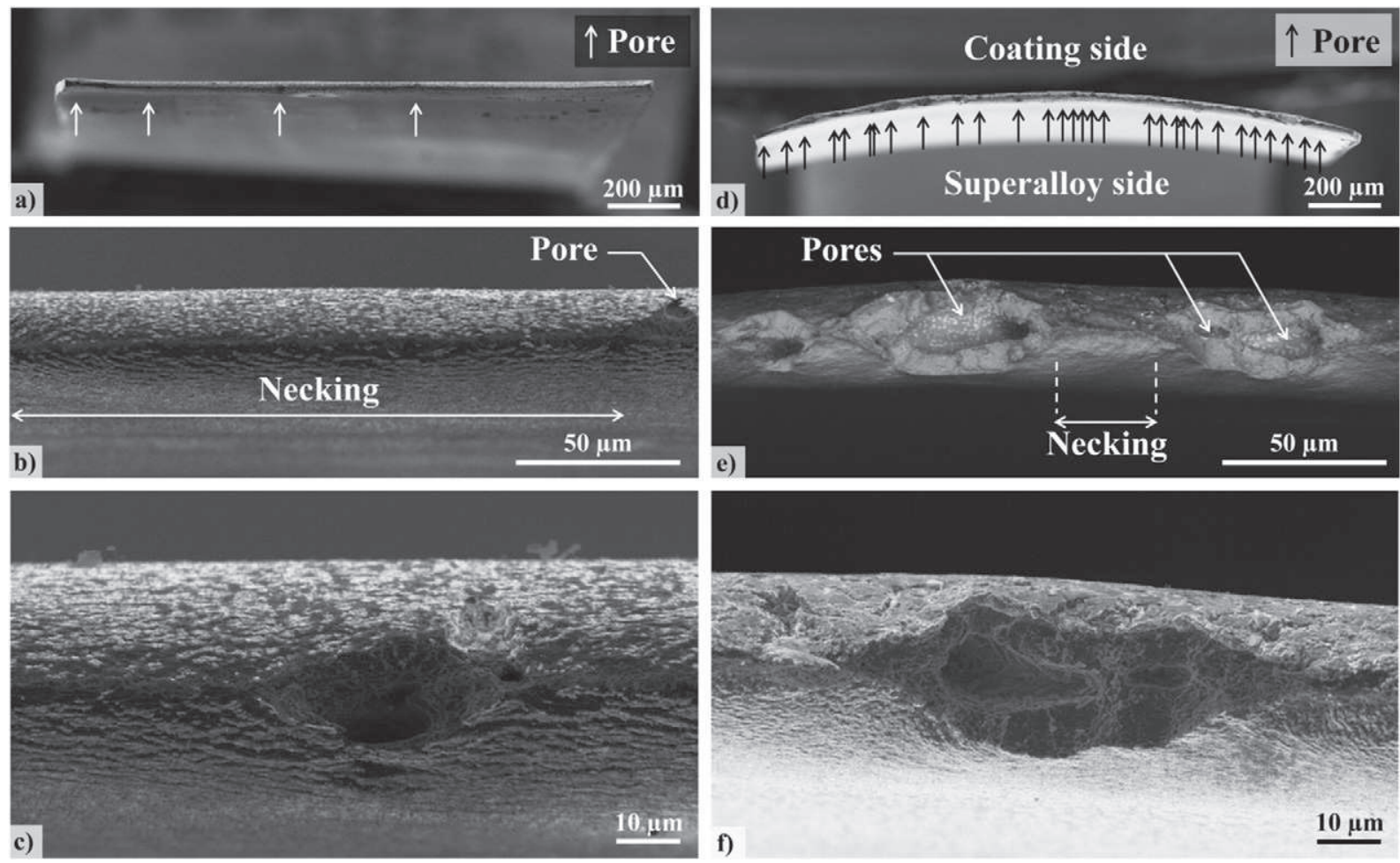

Fig. 8. (a, b and c) Fracture areas of S.Z. specimens after tensile test at $1050{ }^{\circ} \mathrm{C}$ for different magnifications (SEI-SEM). (d, e and f) Fracture areas of ID.Z. specimens after tensile test at $1050{ }^{\circ} \mathrm{C}$ for different magnifications (SEI-SEM)

characterized at high temperatures [18]. The interdiffusion zone thus exhibits intermediate tensile and thermal expansion behaviors with properties lying between those of the coating and those of superalloy above $950{ }^{\circ} \mathrm{C}$. Those intermediate mechanical and thermal expansion behaviors found for the interdiffusion zone may help to assess if this zone can accommodate the different strains of the superalloy and its coating under the combined effects of thermal cycling stresses and applied load. Thermal cycling stresses are mostly encountered in turbine blade service conditions, especially for helicopter applications where operation cycles are relatively short.

The low value of yield stress encountered at high temperature for the interdiffusion zone is below the level of stresses experienced on a real turbine blade. While no creep tests were performed on the interdiffusion zone in the present work, the present tensile results may highlight the poor mechanical strength of the interdiffusion zone in comparison to the superalloy. Due to orders of magnitude between the strain rate during tensile tests and the one of airfoil blades during service $\left(\dot{\varepsilon}_{\text {tensile }}>10^{4} \cdot \dot{\varepsilon}_{\text {airfoilcreep }}\right.$ ), the interdiffusion zone is strongly believed to be a non-load bearing zone in conditions of low stress/high temperature creep. This experimental result confirms the necessity to calculate the "effective stress" after observation of the interdiffusion zone when dealing with mechanical tests performed on coated superalloys [30]. This "effective stress" approach, generally admitted for coatings, was used in models through macroscopic experiments for the design of thin walled airfoil blades [6,7].

As depicted in Fig. 8a and d, a curvature of ID.Z. specimens was observed after fracture while S.Z. specimens remained flat. ID.Z. and S.Z. specimens were flat before testing. The curvature of the ID.Z. specimens results from a lengthening of the interdiffusion zone along the width of the specimen in comparison with the superalloy. Close to the fracture area, an opposite curvature of the specimen was noticed along the uniaxial loading direction. Inversely, this curvature results from a shortening of the interdiffusion zone in comparison with the superalloy. These curvatures demonstrate a difference in thermomechanical properties of the interdiffusion zone compared to those of the superalloy, i.e. thermal expansion and elastic/plastic deformation incompatibilities. According to the database assessed in the present study, we strive to explain these curvatures with different hypotheses. Besides, bilayer models were solved using Abaqus (Version 6.13) to help us in the curvature explanation for the different steps of the high temperature tensile testing. The final curvature obtained with Abaqus simulations is in accordance with experimental observations:

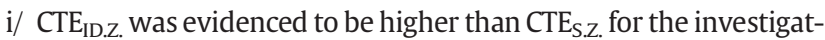
ed temperature range (Table 2). Heating of this graded specimen should result in an isotropic lengthening of the interdiffusion zone in comparison with the superalloy. The curvature of the specimen might be the same along the longitudinal and the width direction. The curvature should be in accordance with the one observed on the fractured area (along the width direction). Due to gripping conditions, the shape predicted by the Abaqus calculation after the heating step is consistent with the final curvature of the specimen. In this bilayer approach, cooling down the specimen does not result in a fully reversible deformation and the specimen keeps the curvatures consistent with the ones obtained experimentally.

ii/ Y.S. ID.z. was shown to be lower than the Y.S.s.z. for the investigated temperature range (Fig. 5). Inversely, the Young modulus of the interdiffusion ( $E_{I D . z .}$ ) zone was noticed to be higher than

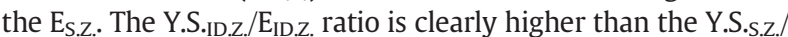
$\mathrm{E}_{\mathrm{S} . \mathrm{z} \text {. }}$ ratio. The interdiffusion zone will then be the first to undergo plastic regime deformations. Shrinkage of the interdiffusion zone due to the Poisson effect might bend a flat plate in opposite curvatures than the one observed in the fracture area. However, Abaqus calculations demonstrate that the high temperature tensile step only has a low effect on the curvature of the specimen in the middle of the gage zone. When unloading, the springback effect increases the curvature of the specimen in this latter region. 
iii/ Due to the higher coefficient of thermal expansion of the interdiffusion zone, cooling down flattens the bilayer specimen but a remaining curvature can still be noticed. The final curvatures along the longitudinal direction and the width direction are in line with experimental observations.

For the purpose of this study, the interdiffusion zone has been considered as a homogenous material. The gradient of microstructure within the interdiffusion zone might induce heterogeneities of mechanical and thermal expansion properties. Because the different layers are too thin to be analyzed separately, their individual properties have not been assessed in the present study.

\subsection{Lower ductility of the interdiffusion zone}

The interdiffusion zone was shown to exhibit a slightly lower ductility compared to the superalloy specimens (Fig. 4). This result may be partly attributed to the higher porosity observed on the ID.Z. specimen fracture surface (Fig. 8). Voids formation during tensile tests at high temperature was previously reported in the literature due to debonding of TCP precipitates [31]. This failure mechanism will be discussed in the following paragraph. The lower ductility of the interdiffusion zone compared to the superalloy might slightly tarnish the accommodation phenomenon previously mentioned (Section 4.1) from a macroscopic point of view. Higher porosity near the interface favors a drop in interfacial toughness and leads to bond-coating/interdiffusion spallation. Riallant et al. recently showed delamination at the substrate/coating interface on a $\beta$-NiAlPt coated AM1 superalloy for a high creep rate regime at high temperature [32]. In the present study, the interdiffusion zone is extracted from an industrial coated superalloy. Therefore the difference in porosity between the interdiffusion zone and the substrate could arise as a consequence of $\mathrm{i} /$ superalloy heterogeneities, ii/ grit-blasting particles coming from the fabrication process, and iii/ interdiffusion during aging heat treatments.

i/ As far as the superalloys' heterogeneities are concerned, porosity in "as received" superalloys results from solidification [33-36] and solution treatment $[34,36,37]$. The primary and secondary dendrite arm spacings in the superalloy are about $330 \mu \mathrm{m}$ and $130 \mu \mathrm{m}$ respectively $[19,38]$. The volume of the elementary pattern for the superalloy is about $0.014 \mathrm{~mm}^{3}$. Consequently, the volume conferred by macroscopic length and width (about $2 \mathrm{~mm}^{3}$ ) comprised about 140 representative patterns of fabrication defects. This hypothesis might be ruled out regarding the statically representative volume of the ID.Z. and S.Z. specimens.

ii/ Large cavities were noticed on ID.Z. specimens' fracture surfaces. Due to the size (15-35 $\mu \mathrm{m})$ and the average spacing between these cavities (30-45 $\mu \mathrm{m}$ ), we can make the hypothesis that grit-blasting particles participate in the fracture mechanism of the ID.Z. specimens. Grit-blasting particles might become dislodged when fracture occurred. Several cross-section observations do not reveal an abnormally high amount of grit-blasting particles compared to literature information. As depicted in Figs. $3 \mathrm{~b}$ and 8 , the fraction of grit-blasting particles at the original coating/substrate interface was relatively important. To our knowledge, no picture of such an interface was reported in the literature. This relatively important fraction of grit-blasting particles might be questioned regarding the impact of the gritblasting procedure on the lifetime of coated superalloys in the case of high stress level/high temperature creep conditions.

iii/ Smaller cavities (2-6 $\mu \mathrm{m})$ also "peppered" the fracture surface of ID.Z. specimens prior to high temperature tensile tests. The occurrence of the voids located at the interface (Figs. 3 and 9) could be due to the lack of accessibility and wettability of the electrolyte during the coating deposition process or to a Kirkendall effect due to the complex interdiffusion between CrAlYTa particles and the Ni,Co matrix as well as between the coating and the superalloy during standard heat treatments. Voids present on the fracture surface of ID.Z. specimens are thought to be inherent to the cross-diffusion during standard heat treatments or the deposition process. They are not thought to form due to deformation at high temperature, as reported earlier in the case of diffusion Pt-aluminide diffusion coatings [31].

\subsection{Comparison of results obtained on free-standing specimens and bulk specimens}

It appears necessary to consider how the mechanical properties of the microtensile specimens are representative of bulk specimens. According to the high surface/volume ratio of microtensile specimens, surface modification due to high temperature oxidation, sublimation, nitriding and elemental depletion, and "size effects" could impact mechanical results. Environmental conditions were controlled to avoid surface degradation at high temperature [18]. As depicted in Fig. 5, mechanical results for free-standing specimens were compared with bulk specimens results reported in the literature. The shaded area illustrates Cormier's results obtained on a bulk MC2 with a similar primary misorientation at strain rate in a range of $10^{-5}$ (bottom limit) to $10^{-4} \mathrm{~s}^{-1}$ (top limit) [23]. Because of the lack of data on the interdiffusion zone in the literature, only the results obtained on the superalloy base material are discussed. All the results obtained on microtensile specimens (yield stress, ultimate tensile strength, and ductility) were slightly lower than those obtained on bulk specimens. The lower mechanical properties measured for ultrathin samples can be attributed to surface softening in the presence of a free surface and/or of stress concentration due to the mechanical gripping of the specimens. In addition, the size of microstructural defects such as pores and particle inclusions

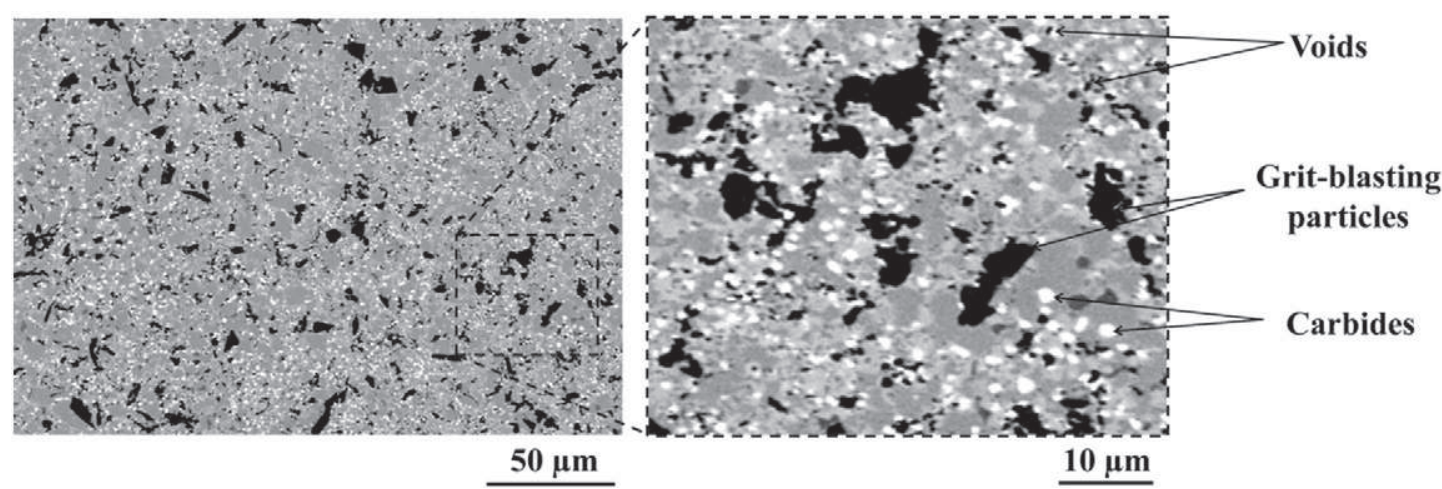

Fig. 9. Observation of the original coating/substrate interface at different magnifications (BSE-SEM). 
are of the same order of magnitude as the thickness of the ultrathin specimens. These defects might affect significantly the tensile properties of ultrathin specimens. Fracture of S.Z. specimens often occurs near grips for the investigated temperature range. Area reduction due to plastic deformation and strain localization due to gripping can be part of the explanation. For the thermal expansion results, the thermal strain of the superalloy as a function of temperature is in line with the literature $[24,28,39]$. The pink and black dashed curves in Fig. 7 correspond respectively to the thermal expansion of the MCrAlY coating [25] and the bulk MC2 [24] obtained on bulk specimens and conventional dilatometers. The tensile properties and thermal expansion properties measured in the present study are in very good agreement with volume behavior and can be used as database for further lifetime and behavior models.

\subsection{Direct application of this accommodation behavior in durability models}

High temperature tensile testing on microtensile free-standing specimens from a real interdiffusion zone presented in this paper is the first attempt reported in the literature. The local characterization of thermal expansion and tensile properties could significantly improve behavior and lifetime predictive models at the micromechanical scale. Durability models of coated systems generally discretize the graded material as a coating/superalloy bimaterial and do not include the interdiffusion zone $[40,41]$. Most of these models describe Top coat/TGO or TGO/ bond coating interface delamination due to rumpling, both of which are the most encountered damage configurations found in service conditions. Even though such damages occur at the interface, the deformation of the bond-coat is partially attributed to the deformation of the substrate. Refining models by incorporating the thermomechanical behavior of the interdiffusion zone might accommodate the creep of the bond-coat. For instance, Pollock et al. implemented an interdiffusion zone in their finite element models for thermomechanical fatigue application by using parametric description depending on the mechanical behavior of both the coating and the interdiffusion zone [42]. Other damage mechanisms such as oxide-assisted crack propagation from a bond-coat also require mechanical properties of the interdiffusion zone.

\subsection{Comparison with other approaches}

Local evolution of mechanical properties can be assessed by several techniques. Other approaches have been performed in the literature to estimate the influence of the gradient of chemical composition associated with an evolution of microstructure on the mechanical response of a superalloy at high temperatures $[4,5,8,9]$. Bensch et al. casted several superalloy single crystals with a nominal composition representative of chemical composition gradients. Standard heat treatments applied to these superalloy single crystals cover several fractions of the $\gamma / \gamma^{\prime}$ microstructure but differ from precipitate morphology in real superalloy microstructure. The fraction evolution of $\gamma^{\prime}$ precipitates underneath the TGO is a mark of volume degradation due to surface degradation. However, vacancies injection associated with oxidation/interdiffusion is also a source of property degradation. The effect of vacancies on the mechanical behavior of materials can be of major importance [43-45]. Despite dealing with a microstructure slightly different from the real microstructure in the case of oxidation damage, this technique has the advantage of dealing with bulk specimens that are conventionally used for database determination. Due to the complexity of the interdiffusion zone microstructure, such layered materials cannot be fabricated as bulk materials. The approach adopted in the present study deals with real microstructures. The specimens tested assess the microstructural features coming from surface/volume degradation. Specific specimen extraction allows testing centimeter long specimens. Concerning local characterization, the technique used in this study finds limitations in specimen thickness. Difficulties to extract specimens thinner than $20 \mu \mathrm{m}$ do not enable assessing the intrinsic behavior of each layer present in the interdiffusion zone. Despite the specimens' very small thickness, width and length, they were large enough to be statistically representative of the global microstructure. Despite a successful atmosphere control, mechanical surface effects like specimen softening due to free surfaces, can be questionable, especially for ultrathin specimens.

The method used in this study can be easily transposed to characterize other functionally graded materials (coated materials, surface damaged by oxidation or corrosion, surface treatment, machining, etc.) Moreover, this technique offers new prospects in terms of local mechanical characterization. This approach appears necessary for implementing real flow rules in the modeling process of functionally graded materials at the micrometric scale.

\section{Conclusions}

1- A specific method for local tensile and thermal expansion characterization at high temperatures has been used to assess physical properties of coated superalloys. High temperature tensile testing on microtensile specimens enables collecting local property results, especially for the interdiffusion zone. These results may be interesting for further numerical models.

2- The interdiffusion zone exhibits intermediate tensile and thermal expansion behaviors in comparison with the behaviors of the MCrAlY coating and the Ni-based single crystal superalloy. This intermediate behavior may reduce thermal strain under thermal cycling stresses widely encountered in service conditions.

3- The non-load bearing behavior of the interdiffusion zone has been evidenced for creep loading at an elevated temperature in this system due to poor mechanical properties at high temperature.

4- Top view observations of the original coating/substrate interface highlighted a significant surface fraction of grit-blasting particles and voids. Such defects could be deleterious to high strain rate creep regime at high temperature that might be responsible of C.Z./ID.Z. spallation.

\section{Acknowledgement}

The authors are particularly grateful to the Turbomeca-SAFRAN group for providing the materials. This work was part of a research program supported by DGA involving the Snecma-SAFRAN group, Turbomeca-SAFRAN, ONERA, CEAT and CNRS laboratories (Mines Paris Tech, Institut Pprime-ENSMA, LMT-Cachan, LMS-X, CIRIMATENSIACET). The authors are indebted to J. Cormier and J.C. Stinville for their numerous helpful suggestions and intense discussions.

\section{References}

[1] C.T. Sims, A history of superalloy metallurgy for superalloy metallurgists, in: R.C. Reed, K.A. Green, P. Caron, T.P. Gabb, M.G. Fahrmann, E.S. Huron, et al. (Eds.),Superalloys 1984, Champion (USA) 1984, pp. 399-419.

[2] R.C. Reed, T. Tao, N. Warnken, Alloys-by-design: application to nickel-based single crystal superalloys, Acta Mater. 57 (2009) 5898-5913.

[3] T. Rhys-Jones, Coatings for blade and vane applications in gas turbines, Corros. Sci. 29 (1989) 623-646.

[4] M. Bensch, C.H. Konrad, E. Fleischmann, C.M.F. Rae, U. Glatzel, Influence of oxidation on near-surface $\gamma^{\prime}$ fraction and resulting creep behaviour of single crystal Ni-base superalloy M247LC SX, Mater. Sci. Eng. A 577 (2013) 179-188.

5] M. Bensch, J. Preußner, R. Hüttner, G. Obigodi, S. Virtanen, J. Gabel, et al., Modelling and analysis of the oxidation influence on creep behaviour of thin-walled structures of the single-crystal nickel-base superalloy René N5 at $980{ }^{\circ} \mathrm{C}$, Acta Mater. 58 (2010) 1607-1617.

[6] M. Brunner, M. Bensch, R. Völkl, E. Affeldt, U. Glatzel, Thickness influence on creep properties for Ni-based superalloy M247LC SX, Mater. Sci. Eng. A 550 (2012) 254-262.

[7] E. Sun, T. Heffernan, R. Helmink, Stress rupture and fatigue in thin wall single crystal superalloys with cooling holes, in: E.S. Huron, R.C. Reed, M.C. Hardy, M.J. Mills, R.E. Montero, P.D. Portella, et al., (Eds.),Superalloys 2012, Champion (USA) 2012, pp. 353-362.

[8] E. Fleischmann, C.H. Konrad, M. Fried, C.M.F. Rae, U. Glatzel, Secondary creep of thinwalled specimens affected by oxidation, in: M. Bensch, E.S. Huron, R.C. Reed, M.C. Hardy, M.J. Mills, R.E. Montero, P.D. Portella, et al., (Eds.),Superalloys 2012, Champion (USA) 2012, pp. 387-394. 
[9] M. Bensch, A. Sato, N. Warnken, E. Affeldt, R.C. Reed, U. Glatzel, Modelling of high temperature oxidation of alumina-forming single-crystal nickel-base superalloys, Acta Mater. 60 (2012) 5468-5480.

[10] B. Passilly, P. Kanoute, F.-H. Leroy, R. Mévrel, High temperature instrumented microindentation : applications to thermal barrier coating constituent materials, Philos. Mag. 86 (2006) 5739-5752.

[11] D. Pan, M.W. Chen, P.K. Wright, K.J. Hemker, Evolution of a diffusion aluminide bond coat for thermal barrier coatings during thermal cycling, Acta Mater. 51 (2003) 2205-2217.

[12] K.J. Hemker, B.G. Mendis, C. Eberl, Characterizing the microstructure and mechanical behavior of a two-phase NiCoCrAlY bond coat for thermal barrier systems, Mater. Sci. Eng. A 483-484 (2008) 727-730.

[13] Z.M. Alam, N. Hazari, V.K. Varma, D.K. Das, Effect of cyclic oxidation exposure on tensile properties of a Pt-aluminide bond-coated Ni-base superalloy, Metall. Mater. Trans. A 42 (2011) 4064-4074.

[14] S. Korte, W.J. Clegg, Micropillar compression of ceramics at elevated temperatures, Scr. Mater. 60 (2009) 807-810.

[15] P. Majerus, PhD dissertation, RWTH Aachen (Germany), 2003, pp. 1-179.

[16] M. Eskner, R. Sandstrom, Measurement of the ductile-to-brittle transition temperature in a nickel aluminide coating by a miniaturised disc bending test technique, Surf. Coat. Technol. 165 (2003) 71-80.

[17] D. Texier, PhD dissertation, INP Toulouse (France), 2013, pp. 1-299.

[18] D. Texier, D. Monceau, J.-C. Salabura, R. Mainguy, E. Andrieu, Micromechanical testing of ultrathin layered material specimens at elevated temperature, Mater. High Temp. 33 (2016) 325-337.

[19] D. Texier, D. Monceau, R. Mainguy, E. Andrieu, Evidence of high-temperature strain heterogeneities in a nickel-based single-crystal superalloy, Adv. Eng. Mater. 16 (2014) 60-64.

[20] P. Caron, T. Khan, Euromat' 89, European Conference on Advanced Materials and Processes, Dev. A New Nickel-Based Single Cryst. Turbine Bl. Alloy Very High Temp., Aachen (Germany) 1989, pp. 333-338.

[21] A. Raffaitin, F. Crabos, E. Andrieu, D. Monceau, Advanced burner-rig test for oxidation-corrosion resistance evaluation of MCrAlY/superalloys systems, Surf. Coat. Technol. 201 (2006) 3829-3835.

[22] H. Biermann, U. Tetzlaff, B. Von Grossmann, H. Mughrabi, V. Schulze, Rafting in monocrystalline nickel-base superalloys induced by shot peening, Scr. Mater. 43 (2000) 807-812.

[23] J. Cormier, PhD dissertation, Université de Poitiers (France), 2006, pp. 1-219.

[24] C. Siret, PhD dissertation, INP Toulouse (France), 2010, pp. 1-236.

[25] A. Boudot, PhD dissertation, INP Toulouse (France), 1999, pp. 1-149.

[26] M.I. Wood, The mechanical properties of coatings and coated systems, Mater. Sci. Eng. A 121 (1989) 633-643.

[27] T.A. Taylor, P.N. Walsh, Dilatometer studies of NiCrAlY coatings, Surf. Coat. Technol. 188-189 (2004) 41-48.
[28] C. Mabru, N. Stephan, R. Chieragatti, Influence of coating on the thermal fatigue resistance of a Ni-based superalloy, Int. J. Damage Mech. 15 (2006) 375-391.

[29] T. Taylor, J. Foster, Thermal expansion of Tribomet MCrAlY coatings, Surf. Coat. Technol. 201 (2006) 3819-3823.

30] J.M. Veys, PhD dissertation, Université de Poitiers (France), 1987, pp. 1-219.

[31] M.Z. Alam, S.V. Kamat, V. Jayaram, D.K. Das, Micromechanisms of fracture and strengthening in free-standing Pt-aluminide bond coats under tensile loading, Acta Mater. 67 (2014) 278-296.

[32] F. Riallant, J. Cormier, A. Longuet, X. Milhet, J. Mendez, High-temperature creep degradation of the AM1/NiAlPt/EBPVD YSZ system, Metall. Mater. Trans. A 45 (2013) $351-360$.

[33] J. Lacaze, A. Hazotte, Directionally solidified materials : nickel-based superalloys for gas turbines, Textures Microstruct. 13 (1990) 1-14.

[34] T. Link, S. Zabler, A. Epishin, A. Haibel, M. Bansal, X. Thibault, Synchrotron tomography of porosity in single-crystal nickel-base superalloys, Mater. Sci. Eng. A 425 (2006) 47-54

[35] E. Bachelet, G. Lesoult, Quality of castings of superalloys, High Temp. Alloy. Gas Turbines, Liege (Belgium) 1978, pp. 665-699.

36] A. Epishin, T.T. Link, U. Bruckner, P.D. Portella, Investigation of porosity in singlecrystal nickel-base superalloys, Mater. Adv. Power Eng. 2002, Liege (Belgium) 2002, pp. 217-226.

[37] B.S. Bokstein, A.I. Epishin, T. Link, V.A. Esin, A.O. Rodin, I.L. Svetlov, Model for the porosity growth in single-crystal nickel-base superalloys during homogenization, Scr. Mater. 57 (2007) 801-804.

[38] D. Texier, D. Monceau, E. Andrieu, Z. Hervier, Creep behaviour of a nickel-based single crystal superalloy at the dendritic scale using micro-tensile specimen, Creep 2012 / JIMIS 11 2012, pp. 1-4.

[39] E. Cavaletti, PhD dissertation, INP Toulouse (France), 2009, pp. 1-265.

[40] M.Y. He, A.G. Evans, J.W. Hutchinson, The ratcheting of compressed thermally grown thin films on ductile substrates, Acta Mater. 48 (2000) 2593-2601.

[41] D.S. Balint, J.W. Hutchinson, An analytical model of rumpling in thermal barrier coatings, J. Mech. Phys. Solids 53 (2005) 949-973.

[42] T.M. Pollock, B. Laux, C.L. Brundidge, A. Suzuki, M.Y. He, Oxide-assisted degradation of Ni-base single crystals during cyclic loading: the role of coatings, J. Am. Ceram. Soc. 94 (2011) s136-s145.

[43] A. Epishin, T. Link, Mechanisms of high temperature creep of nickel-base superalloys under low applied stress, in: K.A. Green, T.M. Pollock, H. Harada, T.E. Howson, R.C Reed, J.J. Schirra, et al., (Eds.),Superalloys 2004, Champion (USA) 2004, pp. 137-143.

[44] S. Dryepondt, D. Monceau, F. Crabos, E. Andrieu, Static and dynamic aspects of coupling between creep behavior and oxidation on MC2 single crystal superalloy at $1150{ }^{\circ} \mathrm{C}$, Acta Mater. 53 (2005) 4199-4209.

[45] B. Viguier, F. Touratier, E. Andrieu, High-temperature creep of single-crystal nickelbased superalloy: microstructural changes and effects of thermal cycling, Philos. Mag. 91 (2011) 4427-4446. 